DOI: $10.4172 / 2469-6676.100043$

\section{Positive Education Calls for Immediate Attention}

\section{The Role of Family in Suicide Cases}

Recently, the number of suicide cases among children and students is rising in Hong Kong. Although the multi-media usually accuses that students are facing tremendous pressure from school, I believe that student suicide is a result of multiple reasons from different aspects. Based on the previous studies, family is one of the most important predictive factors. Children's emotion would be influenced if the relationship among two parents and children become entangled, or children become the scapegoat of the parents' conflicts and are triangulated among parents and children. If such situation continues for a long period of time, especially when pressures from the environment emerges (e.g., academic pressure, peer pressure), children may easily head toward a disastrous result. In addition, children's emotion may be influenced by their parents' emotion. When parents' emotion fluctuates, their children would be like a sponge absorbing parents' emotion. If children keep on staying in such a situation for a long time, their emotions may easily burst out. Furthermore, parents sometimes may label or hurt their children unconsciously. These words will be like a time bomb hidden in a child's heart that may be exploded suddenly. Thus, education toward parents is indispensable.

\section{Importance of Positive Psychology}

Some studies have also shown that even when a child grows up in a less healthy family (e.g., parents abuse their children, have mental health problems, are lack of communication with their child, or the family is dysfunctional), if the child has a solid foundation of resilience, he/she can still reduce anxiety, depression and even suicidal ideation. Therefore, based on the concepts of positive psychology in accordance with Professor Martin Seligman, I propose to implement positive education in schools. His theory suggests that if we can nurture and develop children's 6 virtues (wisdom, courage, humanity, justice, temperance, transcendence) and 24 character strengths (creativity, curiosity and interest of the world, judgment and enlightened thinking, love of learning, insight, courage and bravery, hardworking and perseverance, honesty and sincerity, enthusiasm and energy, the ability to love and be loved, kindness, social intelligence, a sense of citizenship and teamwork, impartiality and justice, leadership, forgiveness, modesty and humility, caution and prudence, self-control and self-regulation, the appreciation of beauty and excellence,
Corresponding author:

Sylvia Kwok Lai Yuk Ching

\section{scyckwok@cityu.edu.hk}

PhD, Associate Professor, Department of Applied Social Sciences, City University of Hong Kong, Hong Kong.

Citation: Ching SKLY. Positive Education Calls for Immediate Attention. Acta Psychopathol. 2016, 2:2

gratitude, hope and a sense of optimism, humor, goals of life and beliefs) as a cornerstone, and to cultivate the child's positive emotions, positive relationships, engagement, accomplishment, meaning of life, physical and mental health, the child's resilience will be greatly enhanced. The child will also be more capable to face with unhappiness and adversity in the life.

\section{Improving Children's Character Strength}

To prevent students' suicidal behaviors, I suggest that schools can use some scales to measure children's level of depression (there's a close relationship between depression and suicide). I suggest referring students with a high risk of depression to social workers or educational psychologists to follow up. For those students who have depressive tendencies, teachers can talk with them and invite other students to be "Secret Angel" and help each other. Teachers can also integrate some elements related to optimism, gratitude, and hope into classes. These years, I launched a number of positive education programs in primary and secondary schools. These projects include topics like how to improve the element of hope and gratitude for primary and secondary school students, how to enhance students' life satisfaction, selfacceptance, sense of control and so on. Our projects also helped to reduce students' anxiety and depression empirically. The studies I conducted in high school also showed that, the higher the students' sense of hope, optimism, gratitude, self-control, and sense of achievement, the greater possibility that their anxiety and depression would be reduced. Recently, I am developing the project to integrate education and musical elements to enhance high school students' sense of hope, problem solving skills and emotional competence. Empirical studies have shown that our programs can reduce high school students' anxiety, depression and suicidal ideation significantly. 


\section{Positive Education in School}

Schools are suggested to implement school-based positive education. Taking primary school as an example, schools can start the project from the school administration and make a five years' strategic plan on school policy. The target of the five-year policy may be related to enhancing students' positive emotions, positive relationships, sense of accomplishment, sense of engagement, positive goals and meanings, physical and psychological health. Moreover, other school policies and curriculum can be adjusted to be in line with this goal. In the first stage, schools can try to incorporate the six elements mentioned above into the self enhancement classes. The project can gradually integrate different themes to different grades in different stages. For example, to enhance positive emotions, we can focus on the emotion awareness and regulation; to enhance the sense of engagement, we can focus on improving children's interests during the whole process of an activity and increase children's intrinsic motivation; for interpersonal relationships, we can help children to develop effective communication with others, so as to establish a harmonious relationship and teamwork; for the sense of accomplishment, we can help children to develop their growth mindset, guiding them to set up and practice their goals; to develop a positive goal and meaning, we can first let them accept and understand their personal values, and then develop their altruistic attitudes; to develop physical and mental health, we can teach them some skills to ventilate their emotion and release their pressure.

Actually, the six pillars of virtues also require the character strengths to be the cornerstone. Besides incorporating these elements into self-enhancement class in each grade, we can also integrate the elements of positive education into formal curriculum. In the second phase of the project, for example, we may ask students to express their emotions, share their family situation and previous experience in music classes. We can also encourage students to share their emotions in art classes. We may incorporate some elements of physical and mental health in physical education. Some computer software can also be used to enhance students' awareness of positive education or character strengths in computer classes. In my university, students have developed a number of computer software and online games, so that students can use the software and games in their spare time or during computer classes. In addition, schools can also incorporate other elements, such as elements of character strengths into the assessment methods. For example, teachers can add some elements related to character strengths in their comments to students. Teachers may indicate that a child loves learning, is perseverant, very brave, or very modest. As for the homework, teachers may allow students to share some of the positive relationships or experience of positive emotions in their weekly-journal. Elements of character strengths and positive education can even be added to the school handbook.

Schools can also set up a "Gratitude Board" and allow students to post their experiences of expressing gratitude to others on the board; the school can develop an "Achievement TV" project. Schools can ask children to make a movie based on their personal experiences and upload it to the "Achievement TV", so that other students can watch the movie. The content of the movie may include very simple topics, such as baking a cake or helping mother with the housework. Moreover, schools can also incorporate elements of positive education in other extracurricular activities, such as general assembly, traveling, camping, even exchange activities. If we can establish an atmosphere of positive education within the whole school, and to build up a positive culture for the school, children will be able to develop their strengths and resilience in such a nurturing environment. More importantly, when they are facing with difficult situations, they will know how to cope with it.

\section{Training on Teachers and Education on Parents}

In order to implement positive education successfully, training on teachers and education on parents are also important. The six pillars of positive education can be incorporated into trainings on teachers and help teachers to understand their own character strengths. In addition, teachers can be trained to have positive emotions, positive relationships, sense of accomplishment, as well as the inspirations in teaching and the meaning of life. When teachers understand and make good use of their own strengths, and when they can master the theoretical framework of positive education, they can live a positive life. At the same time, it can be easier for them to help their students to explore and develop character strengths and other different positive elements. Parents also need to learn some positive discipline methods. For example, parents need to understand their own strengths and how to make use of their own strengths to discipline their children. In this way, parents can help to explore and develop their children's strengths better. Parents can also share and express their emotions and thoughts. They can share their perspectives on their roles and responsibilities, and they can establish a support network among parents. When parents, teachers, schools and all parties can work together to complement each other, the children will grow up in a positive atmosphere. In such a positive atmosphere, children can develop their character strengths and ability to face difficulties and adversity better. Eventually, children's suicidal ideation will be decreased. 